\title{
Características de carcaça e carne de novilhos de diferentes predominâncias genéticas alimentados com dietas contendo níveis de substituição do grão de milho pelo grão de milheto
}

\section{Carcass characteristics of steers of different genetic predominance fed diets containing levels of substitution of corn grain by millet grain}

\author{
Rodrigo Medeiros da Silva ${ }^{1}$; João Restle ${ }^{2}$; Regis Luis Missio ${ }^{3 *}$ \\ Ubirajara Oliveira Bilego ${ }^{4}$; Paulo Santana Pacheco ${ }^{5}$; \\ Pedro Leonardo de Paula Rezende ${ }^{6}$; Juliano José de Resende Fernandes ${ }^{7}$; \\ Alexey Heronville Gonçalves da Silva ${ }^{6}$, João Teodoro Pádua ${ }^{7}$
}

\section{Resumo}

Objetivou-se avaliar as características de carcaça de tourinhos mestiços europeus ou zebuínos, alimentados em confinamento com rações com elevada proporção de concentrado (80\%) contendo diferentes teores de grão de milheto moído em substituição ao grão de milho moído (0, 33, 66 e 100\%). Foram confinados, em 16 baias coletivas, 45 tourinhos com predominância genética Aberdeen Angus e 44 tourinhos com predominância genética Nelore, com peso médio inicial de 317,8 e $320,7 \mathrm{~kg}$, respectivamente, e 21 meses de idade. Ao final do período de confinamento foram abatidos seis animais de cada grupo genético, escolhidos de acordo com o peso corporal e o grau de acabamento médio de cada tratamento. $\mathrm{O}$ delineamento experimental foi inteiramente casualizado, com os tratamentos em arranjo fatorial $4 \times 2$, com seis repetições. A substituição do grão de milho pelo grão de milheto não influenciou significativamente o peso ao abate $(480,4 \mathrm{~kg})$, peso de carcaça quente $(259,5 \mathrm{~kg})$, rendimento de carcaça quente $(54,1 \%)$ e espessura de gordura subcutânea $(3,95 \mathrm{~mm})$. Tourinhos com predominância genotípica Aberdeen Angus apresentaram valores significativamente superiores para peso ao abate (507,6 vs 453,3 $\mathrm{kg}$ ), peso de carcaça quente (269,6 vs $249,3 \mathrm{~kg}$ ) e área do músculo longissimus dorsi $(65,34$ vs 56,83 $\left.\mathrm{cm}^{2}\right)$, porém, foram inferiores quanto ao rendimento de carcaça quente (53,2 vs 55,0 \%). O grão de milheto pode ser utilizado em substituição ao grão de milho, pois não altera as principais características de carcaça de interesse econômico de novilhos terminados em confinamento.

Palavras-chave: Aberdeen Angus, gordura de cobertura, Nelore, peso de carcaça, traseiro especial

${ }^{1}$ Prof., Universidade Estadual de Goiás, UEG, São Luís de Montes Belos, GO. E-mail: rodrigo.medeiros@ueg.br

2 Bolsista PVNS CAPES, Fundação Universidade Federal do Tocantins, UFT, Araguaína, TO. E-mail: jorestle@terra.com.br

${ }^{3}$ Prof., Dept ${ }^{\circ}$ de Agronomia, Universidade Tecnológica Federal do Paraná, UTFPR, Pato Branco, PR. E-mail: regisluismissio@, gmail.com

${ }^{4}$ Pesquisador, Cooperativa Agroindustrial dos Produtores Rurais do Sudoeste Goiano, Rio Verde, GO. E-mail: birabilego@ hotmail.com

${ }^{5}$ Prof., Dept ${ }^{\circ}$ de Zootecnia, Universidade Federal de Santa Maria, UFSM, Santa Maria, RS. E-mail: pacheco.dz.ufsm@hotmail. com

${ }^{6}$ Discentes do Curso de Doutorado e Mestrado do Programa de Pós-Graduação em Ciência Animal, UFG, Goiânia, GO. E-mail: pedrozootec@hotmail.com; alexheron@uol.com.br

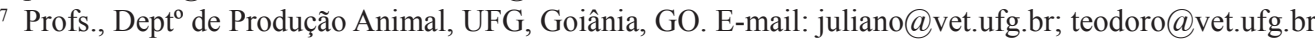

* Autor para correspondência 


\begin{abstract}
This study aimed to assess the carcass characteristics of European crossbred young bulls or Zebu feedlot finished with diets with high percentage of concentrate $(80 \%)$ containing different levels of pearl millet grain as replacement for corn grain $(0,33,66$ and 100\%). Forty-five young bulls with genotype predominance of Aberdeen Angus and forty-four young bulls with genotype predominance Nellore with average initial weight of 317.8 and $320.7 \mathrm{~kg}$, respectively, and average age of $21 \mathrm{month}$, were allocated in 16 collective pens. At the end of the finishing period were slaughtered six animals of each genetic group, chosen according to the body weight and degree of finishing each treatment. The experimental design was the completely randomized design with treatments in a $4 \times 2$ factorial arrangement using six replicates. The replacement of corn grain by millet grain did not significantly influence slaughter weight (480.4 kg), hot carcass weight $(259.5 \mathrm{~kg})$, carcass yield (54.1\%) and subcutaneous fat thickness (3.95 $\mathrm{mm}$ ). Young bulls with genotype predominance of Aberdeen Angus showed significantly higher values for slaughter weight (507.6 vs. $453.3 \mathrm{~kg}$ ), hot carcass weight (269.6 vs. $249.3 \mathrm{~kg}$ ) and longissimus dorsi area (65.34 vs $\left.56.83 \mathrm{~cm}^{2}\right)$, however, were lower in carcass yield (53.2 vs. 55.0\%). Millet grain can be used in substitution to corn grain for finishing steers since it does not change carcass traits of economic interest.
\end{abstract}

Key words: Aberdeen Angus, carcass weight, Nellore, pistol cut, subcutaneous fat

\section{Introdução}

Diante da conjuntura da pecuária brasileira, caracterizada pelos elevados custos de produção e redução histórica do preço pago pelo boi pronto para abate (ANUALPEC, 2014), os produtores buscam alternativas que propiciem aumento da eficiência econômica de seus sistemas de produção. O confinamento, nesse sentido, como uma das alternativas para a intensificação da atividade pecuária, necessária para a competitividade do sistema de produção, possibilita incrementos na taxa de desfrute, bem como a terminação de animais no período de entressafra e a maior remuneração. A utilização dessa estratégia em sistemas de produção com integração lavoura pecuária e/ou próximo de regiões produtoras de grãos pode possibilitar índices de lucratividade ainda melhores em função da oferta de alimentos (forragens, grãos e subprodutos) de menores custos.

O milheto, como uma cultura de sucessão, tem sido muito utilizado na região Centro Oeste após o cultivo da soja, para pastejo e produção de palhada, para o plantio direto, para produção de grãos em substituição a cultura do milho (de maior risco na safrinha) e/ou para produção de silagem (BERGAMASCHINE et al., 2011). O grão de milheto, nesse contexto, é mais uma alternativa para a alimentação de bovinos, podendo contribuir para contornar a baixa margem de lucro em confinamento em função do menor custo em relação ao grão de milho. Isso pode ser possível, visto que é esperado que bovinos alimentados com grão de milheto e/ou misturas de grão de milho com grão de milheto tenham desempenho similar àqueles alimentados com dietas tradicionais, em que se utilizam grãos de milho ou sorgo, ou ambos (HILL et al., 1996). Entretanto, apesar do milheto apresentar grande potencial para a alimentação de ruminantes, esse grão está envolvido em número limitado de estudos relacionados com a alimentação de bovinos de corte, não existindo na literatura consultada, resultados relacionando sua utilização com as características de carcaça de bovinos.

Com relação ao genótipo bovino, animais de raças europeias especializadas para a produção de carne apresentam carcaças com maior musculosidade enquanto que zebuínos apresentam maior conteúdo de gordura (VAZ et al., 2005). Isso ocorre em função do maior peso adulto dos genótipos europeus, os quais são mais jovens fisiologicamente a um mesmo peso corporal e, com isso, apresentam maior síntese proteica e menor depósito de gordura (Di MARCO; BARCELLOS; COSTA, 2007). No entanto, bovinos europeus apresentam normalmente maiores taxas 
de ganho de peso e, sendo essas determinantes da taxa de depósito de gordura (NRC, 1996), podem apresentar, a um mesmo peso corporal e/ou idade cronológica, similar acabamento de carcaça que animais com predominância zebuína (PACHECO et al., 2005a, b), desde que o aporte nutricional não seja limitante.

Além dos aspectos mencionados deve-se destacar que zebuínos são menos tolerantes às elevadas proporções de grãos e/ou concentrado na dieta (maior exigência de fibra longa na dieta), o que pode limitar seu desempenho em confinamento (ALMEIDA et al., 2010). Dessa forma, a utilização de alimentos com menores teores de carboidratos não fibrosos em dietas com altos teores de concentrado podem favorecer o desenvolvimento corporal desses genótipos. Todavia, a redução dessas frações nas dietas pode se refletir em redução do aporte energético ao animal, o qual assume grande importância sobre a deposição de gordura, bem como para a composição tecidual das carcaças (BERG; BUTTERFIELD, 1976; PETHICK; HARPER; ODDY, 2004). Face ao exposto, objetivou-se avaliar a inclusão de milheto em substituição ao milho em quatro índices percentuais na ração de bovinos com predominância genotípica Aberdeen Angus ou Nelore sobre as características quantitativas e qualitativas da carcaça.

\section{Material e Métodos}

O trabalho foi desenvolvido entre 14 de agosto e 11 de novembro de 2010, nas instalações do Setor de Bovinocultura de Corte do Centro Tecnológico da Cooperativa Agroindustrial dos Produtores Rurais do Sudoeste Goiano, no município de Rio Verde/GO, localizado a $17^{\circ} 46^{\prime} 22^{\prime \prime}$ de latitude Sul e $51^{\circ} 02^{\prime} 86^{\prime \prime}$ de longitude Oeste e, 815 metros de altitude. Foram utilizados 45 tourinhos com predominância genotípica Aberdeen Angus e 44 tourinhos com predominância genotípica Nelore, com peso médio inicial de 317,8 e $320,7 \mathrm{~kg}$, respectivamente. Os animais apresentaram idade média inicial, avaliada pela dentição, de aproximadamente 21 meses. Esses foram confinados em baias coletivas $\left(77 \mathrm{~m}^{2}\right)$, equipadas com bebedouros e comedouros, sendo o piso a base de cascalho, com declive de $5 \%$. Antecedendo o período experimental, os animais foram submetidos ao controle de endoparasitas e ectoparasitas e vacinados contra pasteurelose.

Os animais, de cada predominância genética, foram distribuídos aleatoriamente, após sete dias de adaptação às condições experimentais, para receberem uma das rações experimentais (Tabela 1). No início do experimento e a cada 28 dias os animais foram pesados individualmente após jejum de sólidos e líquidos por 16 horas, sendo o período experimental de 89 dias. As rações avaliadas foram compostas por diferentes teores de grão de milheto em substituição ao grão de milho com os diferentes grupos genéticos, que foram determinados por meio de avaliação das características fenotípicas dos animais.

As rações foram balanceadas para ganho de peso de 1,5 kg/dia, estimando-se o consumo de 2,4\% do peso corporal (NRC, 1996). O consumo foi registrado diariamente, mantendo-se as sobras em torno de $10 \%$ por meio da pesagem das sobras do dia anterior. As rações foram fornecidas em duas refeições diárias $(09 \mathrm{~h} 00$ e 17h00), com a mistura do volumoso e do concentrado no comedouro. Para determinação da composição química das rações, semanalmente foram coletadas amostras dos alimentos, as quais foram pré-secas em estufa com ventilação forçada de ar a $55^{\circ} \mathrm{C}$ por 72 horas. Após as amostras foram moídas em moinho tipo Willey dotado com peneira com crivos de $1 \mathrm{~mm}$ e armazenadas em potes plásticos para posteriores análises químicas (Tabela 1). Os teores de matéria seca (MS), matéria mineral (MM), proteína bruta (PB) e extrato etéreo (EE) foram determinados segundo AOAC (1990). Os teores de nitrogênio insolúvel em detergente neutro (NIDN) e insolúvel em detergente ácido (NIDA) foram determinados segundo Licitra, Hernandez e Van Soest (1996). O teor de fibra em detergente neutro (FDN) foi determinado segundo Van Soest, Robertson e Lewis 
(1991), sendo corrigida para cinzas e proteínas. Os teores de fibra em detergente ácido e lignina foram determinados segundo Van Soest (1973). Os teores de carboidratos totais (CT) e carboidratos não fibrosos (CNF) foram determinados segundo o NRC (2001): $\mathrm{CT}=100-(\% \mathrm{~PB}+\% \mathrm{FDNcp}+\% \mathrm{EE}+\% \mathrm{MM})$ e CNF
$=100-(\%$ FDNcp $+\% \mathrm{~PB}+\% \mathrm{EE}+\% \mathrm{MM}) . \mathrm{O}$ teor de nutrientes digestíveis totais (NDT) foi estimado segundo Cappelle et al. (2001): NDT $=83,79$ $(0,4171 *$ FDN $)$. O teor de amido dos alimentos e das rações foi determinado segundo metodologia proposta por Silva e Queiroz (2002).

Tabela 1. Composição percentual e química das rações (em base da matéria seca).

\begin{tabular}{lcccc}
\hline \multicolumn{1}{c}{ Itens } & \multicolumn{4}{c}{$\%$ de milheto na dieta } \\
\cline { 2 - 4 } \multicolumn{1}{c}{0} & 33 & 66 & 100 \\
\hline Silagem de milho, \% da MS & 20,00 & 20,02 & 20,00 & 20,02 \\
Milho, \% da MS & 70,50 & 48,96 & 25,06 & 0,00 \\
Milheto, \% da MS & 0,00 & 24,05 & 49,88 & 77,47 \\
Farelo de soja, \% da MS & 8,02 & 5,49 & 3,61 & 1,19 \\
Uréia, \% da MS & 0,62 & 0,63 & 0,60 & 0,49 \\
Núcleo mineral', \% da MS & 0,86 & 0,85 & 0,85 & 0,83 \\
Matéria seca, \% MN & 66,04 & 66,22 & 66,46 & 66,67 \\
Matéria mineral, \% MS & 1,54 & 1,67 & 1,54 & 1,96 \\
Proteína bruta, \% MS & 14,19 & 14,16 & 14,45 & 6,18 \\
Extrato etéreo, \% MS & 3,36 & 2,82 & 5,46 & 15,74 \\
FDN, \% MS & 11,69 & 12,71 & 14,98 & 12,74 \\
FDNcp, \% MS & 10,66 & 10,34 & 12,13 & 2,778 \\
FDA, \% MS & 2,28 & 2,33 & 2,32 & 1,23 \\
Lignina, \% MS & 0,82 & 0,94 & 1,08 & 0,29 \\
NIDM, \% do N total & 0,08 & 0,14 & 0,21 & 0,06 \\
NIDA, \% do N total & 0,02 & 0,03 & 0,05 & 79,39 \\
CT, \% MS & 80,38 & 80,21 & 79,69 & 64,48 \\
CNF, \% MS & 70,25 & 71,01 & 66,42 & 77,69 \\
Amido, \% MS & 70,76 & 75,58 & 59,92 & 77,54 \\
NDT, \% MS & 78,91 & 78,48 & & 77,22 \\
\hline
\end{tabular}

${ }^{1}$ Níveis de garantia (g/kg): Ca 117,00 - 130,00 g; P - 61,00 g; S - 9,00 g; Na - 150,00 g; Mg - 0,694 g; Zn - 5,783 mg; Mn - 1,0 g; $\mathrm{Cu}$ - 1,88 g; Co - 0,160 g; I - 0,165 g; Se - 0,025 g; Monensina sódica - 2,40 g; MN = matéria natural; MS = matéria seca; FDN = fibra em detergente neutro $(\mathrm{FDN}) ; \mathrm{FDNcp}=$ FDN corrigida para cinzas e proteína; NIDM = nitrogênio insolúvel em detergente neutro; NIDA = nitrogênio insolúvel em detergente ácido; $\mathrm{CT}=$ carboidratos totais; $\mathrm{CNF}=$ carboidratos não fibrosos; NDT $=$ nutrientes digestíveis totais.

Fonte: Elaboração dos autores.

Ao final do período de confinamento, foram escolhidos de acordo com o peso corporal e o grau de acabamento médio de cada tratamento seis animais, que foram abatidos em frigorífico comercial, seguindo o fluxo normal na linha de abate. Nesses animais procederam-se as avaliações de carcaça, enquanto que os aspectos relacionados com o desempenho animal foram publicados por
Silva et al. (2014), utilizando-se os 89 animais. Assim, antecedendo o abate os animais foram submetidos a jejum completo por 16 horas. Após o abate, as carcaças foram identificadas, divididas ao meio e pesadas para determinação do rendimento de carcaça quente, lavadas e levadas ao resfriamento por 24 horas em temperatura variando entre 0 e $2^{\circ} \mathrm{C}$. Após o resfriamento, as carcaças foram pesadas 
e avaliadas quanto à conformação e maturidade fisiológica segundo Müller (1987). O rendimento de carcaça quente foi obtido pela relação entre o peso de carcaça quente e o peso de fazenda.

$\mathrm{Na}$ meia-carcaça direita foram realizadas primeiramente as medidas métricas: espessura de coxão, medida com auxílio de compasso posicionado entre a face lateral e a medial da porção superior do coxão; comprimento de perna, desde a articulação tíbio-tarsiana até o bordo anterior do osso do púbis; comprimento de braço, da articulação rádio-carpiana até a extremidade do olécrano; e perímetro de braço, envolvendo a parte média do rádio-cúbito e os músculos que recobrem a região. Nessa meia carcaça direita foi realizado um corte entre a $11^{\mathrm{a}}$ e $12^{\mathrm{a}}$ costelas com intuito de expor o músculo longissimus dorsi para determinação da área desse músculo, com auxílio de planímetro. No mesmo local, foi determinada a espessura de gordura subcutânea, obtida pela média aritmética de três observações.

A meia carcaça esquerda, por sua vez, foi separada em cortes primários, onde o dianteiro foi separado do traseiro e a ponta de agulha entre a $5^{\mathrm{a}} \mathrm{e}$ $6^{a}$ costela, incluindo pescoço, paleta, braço e cinco costelas. Através de corte das costelas a $22 \mathrm{~cm} \mathrm{da}$ coluna vertebral separou-se o traseiro especial da ponta de agulha que incluiu as costelas a partir da sexta, mais os músculos abdominais. Depois de separados, os cortes foram pesados, determinandose o peso relativo à meia-carcaça.

$\mathrm{O}$ delineamento experimental utilizado foi o inteiramente casualizado, com os tratamentos em arranjo fatorial $4 \times 2$ (quatro rações e dois grupos genéticos), com seis repetições. Os dados foram submetidos à análise de variância, correlação, regressão e teste para a falta de ajuste das equações de regressão (lack-of-fit), utilizando-se o PROC REG do SAS (Statistical Analysis System, versão 9.2). Quando os dados não se ajustaram aos modelos de regressão, as médias foram comparadas pelo teste Tukey, considerando-se $\alpha=5 \%$. O peso inicial foi utilizado como co-variável, quando não significativo foi retirado do modelo. O modelo matemático geral utilizado foi: $\gamma_{\mathrm{ijk}}=\mu+\tau_{\mathrm{i}}+\beta_{\mathrm{j}}+$ $(\tau \beta)_{\mathrm{ij}}+£_{\mathrm{k}}+\varepsilon_{\mathrm{ijkl}}$ em que: $\gamma_{\mathrm{ijkl}}=$ variável dependente; $\mu=$ média geral; $\tau_{\mathrm{i}}=$ efeito das dietas; $\beta_{\mathrm{j}}=$ efeito do grupo genético $\mathrm{j} ;(\tau \beta)_{\mathrm{ij}}=$ interação entre dieta i e grupo genético $\mathrm{j} ; £_{\mathrm{k}}=$ efeito da co-variável $\mathrm{m}$ $; \varepsilon_{\mathrm{ijkl}}=$ erro experimental residual. No estudo de regressão, o modelo foi: $\gamma_{\mathrm{ij}}=\beta_{0}+\beta_{1} \mathrm{X}_{\mathrm{i}}+\beta_{2} \mathrm{X}_{\mathrm{i}}^{2}+$ $\beta_{3} X_{i}^{3}+\alpha_{j+} \varepsilon_{i j}$, onde: $\gamma_{i j}=$ variáveis dependentes; $\beta$ 's $=$ coeficientes de regressão; $X_{i}=$ variáveis independentes; $\alpha_{j}=$ desvios da regressão; e $\varepsilon_{\mathrm{ij}}=$ erro aleatório residual.

\section{Resultados e Discussão}

Não foi verificada interação $(\mathrm{P}>0,05)$ entre o teor do grão de milheto em substituição ao de milho e grupos genéticos para as variáveis avaliadas. O peso ao abate não foi influenciado $(\mathrm{P}>0,05)$ pelo grão de milheto em substituição ao de milho (Tabela 2), o que foi determinado pelo similar pelo ganho de peso médio diário $(1,75$; $1,58 ; 1,75$ e $1,56 \mathrm{~kg} / \mathrm{dia})$ e similar consumo de matéria seca $(2,25 ; 2,17 ; 2,30$ e $2,23 \%)$ para os animais em dietas com rações contendo 0, 33, 66 e $100 \%$ de milheto, respectivamente (SILVA et al., 2014). Todavia, os novilhos com predominância genética Aberdeen Angus apresentaram maior $(\mathrm{P}<0,05)$ peso ao abate em relação aos com predominância genética Nelore, resultado do maior ganho de peso médio diário $(2,10$ vs 1,50 $\mathrm{kg} /$ dia) para os primeiros. Esses resultados foram semelhantes aos divulgados por Restle et al. (1999) e Vaz et al. (2002), os quais verificaram que animais com predominância Charolês superaram aqueles com predominância genética Nelore quanto ao peso de abate. Corroborando, Perotto, Abrahão e Moletta (2000) destacaram que animais com predominância genética europeia, produtos de cruzamentos terminais de touros Bos taurus $\mathrm{x}$ vacas F1 Bos Taurus x Nelore, são alternativas do uso de recursos genéticos para aumentar a produção de carne, notadamente nos rebanhos de corte do Brasil Central. 
Tabela 2. Variáveis referentes as características quantitativas da carcaça de novilhos com predominância Aberdeen Angus (A) ou Nelore (N) alimentados com rações contendo teores de grão de milheto em substituição ao grão de milho.

\begin{tabular}{|c|c|c|c|c|c|c|c|c|c|}
\hline \multirow{2}{*}{ GG } & \multicolumn{4}{|c|}{$\%$ de milheto na dieta } & \multirow{2}{*}{ Média } & \multirow{2}{*}{$\mathrm{CV}$} & \multicolumn{3}{|c|}{ Fontes de variação } \\
\hline & 0 & 33 & 66 & 100 & & & $\mathrm{M}$ & GG & $\mathrm{M} * \mathrm{G}$ \\
\hline \multicolumn{10}{|c|}{ Peso de abate, $\mathrm{kg}$} \\
\hline A & 517,40 & 495,70 & 515,40 & 501,70 & 507,60 & & & & \\
\hline $\mathrm{N}$ & 461,20 & 452,70 & 440,30 & 459,00 & 453,30 & 6,45 & 0,311 & $<0,000$ & 0,384 \\
\hline Média & 489,20 & 474,20 & 477,80 & 480,30 & 480,40 & & & & \\
\hline \multicolumn{10}{|c|}{ Peso de carcaça quente, $\mathrm{kg}$} \\
\hline A & 271,60 & 262,50 & 272,60 & 271,60 & 269,58 & & & & \\
\hline $\mathrm{N}$ & 254,80 & 249,20 & 236,50 & 256,60 & 249,28 & 6,52 & 0,141 & $<0,001$ & 0,254 \\
\hline Média & 263,20 & 255,85 & 254,55 & 264,10 & 259,43 & & & & \\
\hline \multicolumn{10}{|c|}{ Peso de carcaça fria, $\mathrm{kg}$} \\
\hline A & 265,79 & 256,83 & 266,28 & 266,47 & 263,84 & & & & \\
\hline $\mathrm{N}$ & 245,65 & 243,84 & 229,19 & 252,60 & 242,80 & 7,32 & 0,082 & $<0,001$ & 0,251 \\
\hline Média $^{1}$ & 255,66 & 250,34 & 247,66 & 259,54 & 253,30 & & & & \\
\hline \multicolumn{10}{|c|}{ Rendimento de carcaça quente, $\%$} \\
\hline A & 52,49 & 52,96 & 52,89 & 54,14 & 53,11 & & & & \\
\hline $\mathrm{N}$ & 55,25 & 55,05 & 53,71 & 55,90 & 54,99 & 3,06 & 0,246 & $<0,001$ & 0,492 \\
\hline Média & 53,80 & 53,95 & 53,28 & 54,99 & 54,00 & & & & \\
\hline \multicolumn{10}{|c|}{ Rendimento de carcaça fria, $\%$} \\
\hline A & 51,37 & 51,81 & 51,66 & 53,11 & 51,98 & & & & \\
\hline $\mathrm{N}$ & 53,26 & 53,86 & 52,05 & 55,03 & 53,56 & 2,96 & 0,049 & 0,002 & 0,547 \\
\hline Média $^{2}$ & $52,26 \mathrm{bc}$ & $52,79 \mathrm{ab}$ & $51,83 \mathrm{bc}$ & $54,04 \mathrm{a}$ & 52,73 & & & & \\
\hline \multicolumn{10}{|c|}{ Quebra ao resfriamento, $\%$} \\
\hline A & 2,14 & 2,16 & 2,32 & 1,89 & 2,13 & & & & \\
\hline $\mathrm{N}$ & 3,59 & 2,15 & 3,09 & 1,56 & 2,60 & 30,05 & 0,011 & 0,179 & 0,056 \\
\hline Média & $2,87 \mathrm{ab}$ & $2,16 b c$ & $2,71 \mathrm{ab}$ & $1,73 b$ & 2,36 & & & & \\
\hline
\end{tabular}

$\mathrm{M}=\%$ de milheto na dieta; $\mathrm{GG}=$ grupo genético; $\mathrm{M}^{*} \mathrm{G}=$ interação entre fatores; médias seguidas de letras distintas, na linha, diferem entre si pelo teste Tukey.

Fonte: Elaboração dos autores.

Os pesos de carcaça quente e fria não foram alterados $(\mathrm{P}>0,05)$ pelo avanço do teor de grão de milheto na dieta (Tabela 2), resultado do similar ganho de peso médio diário $(\mathrm{r}=0,35$ e $\mathrm{r}=0,36$, respectivamente) e peso dos animais ao abate $(\mathrm{r}=$ 0,95 e $r=0,94$, respectivamente) (Tabela 3 ). Os pesos de carcaça quente e fria foram altamente correlacionados entre si $(r=0,99)$, apresentando correlações moderadas a altas $(\mathrm{P}<0,05)$ com a área do longissimus dorsi $(\mathrm{r}=0,52$ e $\mathrm{r}=0,52$, respectivamente), conformação $(r=0,50$ e $r=0,41$, respectivamente), espessura de coxão $(\mathrm{r}=0,52 \mathrm{e}$ 0,51 , respectivamente), perímetro de braço $(\mathrm{r}=0,70$ e $r=0,66$, respectivamente), dianteiro $(r=0,99$ e $r$ $=0,99$, respectivamente), ponta de agulha $(\mathrm{r}=0,98$ e $r=0,99$, respectivamente) e traseiro especial ( $r=$ 0,96 e $r=0,99$, respectivamente). Esses resultados demonstraram que, de forma geral, o peso de carcaça foi reflexo do depósito de tecidos na carcaça, especialmente de músculo, já que os animais eram machos não castrados. 


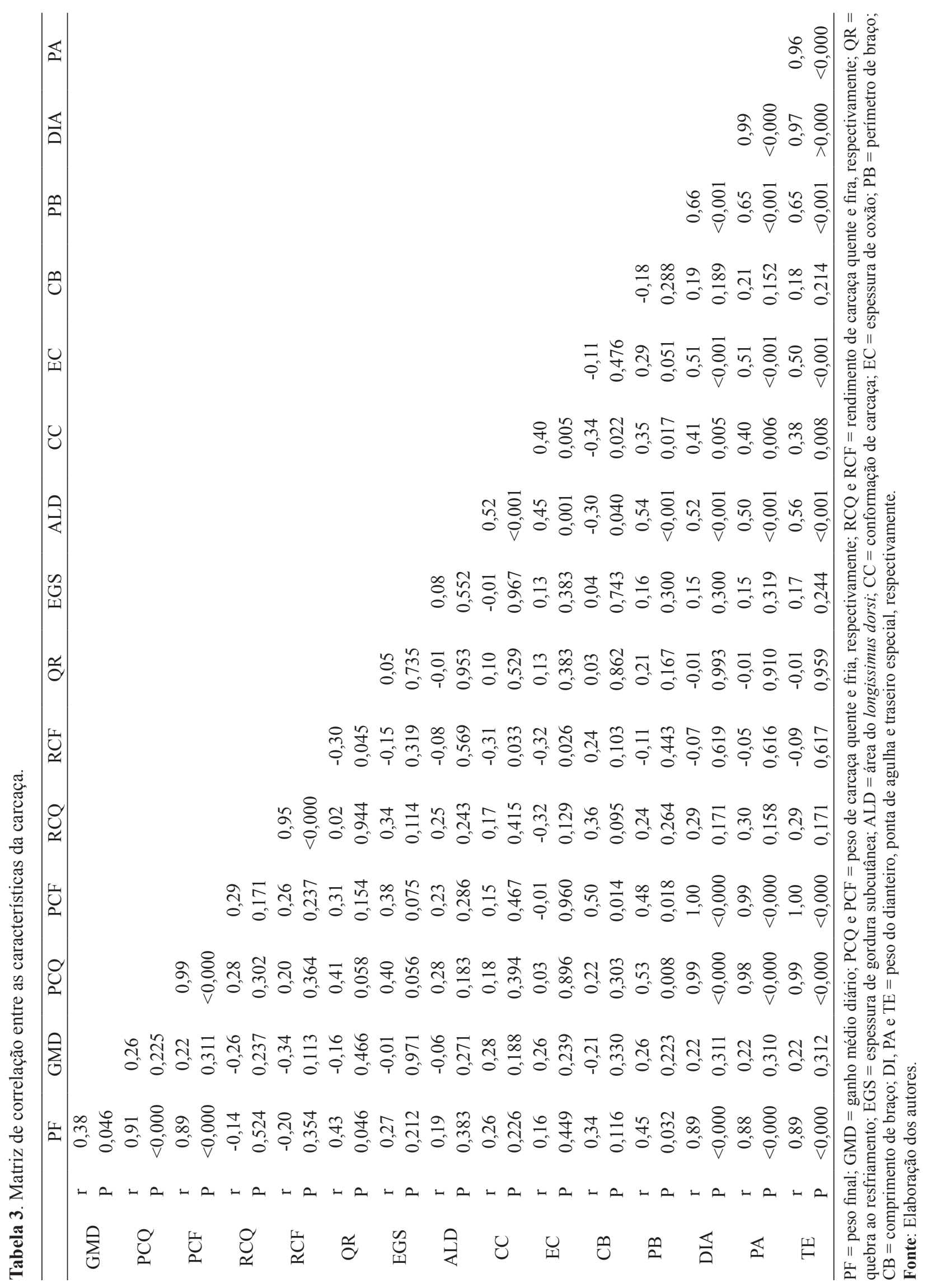


As predominâncias genéticas influenciaram $(\mathrm{P}<0,05)$ os pesos de carcaça quente e fria, em que novilhos com predominância genética Aberdeen Angus apresentaram carcaças mais pesadas, antes e depois do resfriamento (Tabela 2), fato associado ao maior peso ao abate para os animais desse grupo genético. Resultados similares ao do presente estudo são comumente encontrados na literatura (PEROBELLI; RESTLE; MULLER, 1995; RESTLE et al., 2000, 2002), desde que os animais não sejam abatidos com o mesmo peso corporal, independentemente do rendimento de carcaça. Corroborando, Wheeler et al. (1996) concluíram que a uma mesma idade ou grau de acabamento, o peso de carcaça é maior em novilhos filhos de touro europeus e, a uma mesma idade, peso corporal ou grau de marmoreio, novilhos filhos de touros zebuínos apresentam maior rendimento de carcaça.

Considerando as predominâncias genéticas (Tabela 4), verificou-se que os pesos de carcaça quente e fria, nos novilhos com predominância zebuína (Nelore), foram correlacionados, respectivamente, com o peso ao abate $(\mathrm{r}=0,95 \mathrm{e}$ $r=0,92)$, espessura de coxão $(r=0,61$ e $r=0,62)$, comprimento $(\mathrm{r}=0,50$ e $\mathrm{r}=0,53)$ e perímetro de braço $(r=0,74$ e $r=0,71)$, peso do dianteiro $(r=$ $0,99$ e $r=0,99)$, peso da ponta de agulha $(r=0,99$ e $r=0,99)$ e peso do traseiro especial $(r=0,91$ e $r$ $=0,92$ ) e, nos novilhos com predominância genética europeia (Aberdeen Angus), com o peso ao abate ( $\mathrm{r}$ $=0,91$ e $\mathrm{r}=0,85)$, perímetro de braço $(\mathrm{r}=0,53$ e $\mathrm{r}$ $=0,48)$, peso do dianteiro $(r=0,99$ e $r 1,00)$, peso da ponta de agulha $(r=0,98$ e $r=0,99)$ e peso do traseiro especial ( $r=0,99$ e $r=1,00)$, inferindo que, nos animais com predominância genética Aberdeen
Angus, o depósito dos tecidos nos cortes comerciais assumiu maior importância sobre o peso de carcaça, enquanto que o tamanho e a forma da carcaça, bem como o peso de abate, apresentaram maior importância para o peso de carcaça nos novilhos com predominância genética Nelore.

O rendimento de carcaça quente não foi alterado $(\mathrm{P}>0,05)$ pelo avanço do teor de grão de milheto na dieta (Tabela 2). Por outro lado, o rendimento de carcaça fria foi maior $(\mathrm{P}>0,05)$ nas dietas com $100 \%$ de milheto, as quais foram similares às dietas com $33 \%$ de milheto e, essas com as demais dietas. Esses resultados foram possivelmente associados à variação na quebra ao resfriamento ( $r=-0,30$; Tabela 3 ), em que as maiores perdas de líquidos ao resfriamento coincidiram com os menores rendimentos de carcaça fria. Os rendimentos de carcaça quente e fria apresentaram correlações $(\mathrm{P}<0,05)$, de médias a baixas (Tabela $3)$, com a conformação ( $\mathrm{r}=-0,31$ e $\mathrm{r}=-0,31$, respectivamente) e espessura de coxão $(r=-0,34$ e $r$ $=-0,32$, respectivamente). Esses resultados podem estar indicando que o aumento da conformação e espessura de coxão influenciou o rendimento de carcaça indiretamente, já que o aumento da massa muscular pode resultar em maior acúmulo de líquidos (Di MARCO, BARCELLOS; COSTA, 2007) e, estando o rendimento de carcaça fria associado à perda de líquidos, resultar em menores rendimentos de carcaça. No entanto, segundo Kuss et al. (2005), o aumento da hipertrofia muscular normalmente resulta em menor perda de líquidos ao resfriamento, em função de reduzir a superfície específica. 


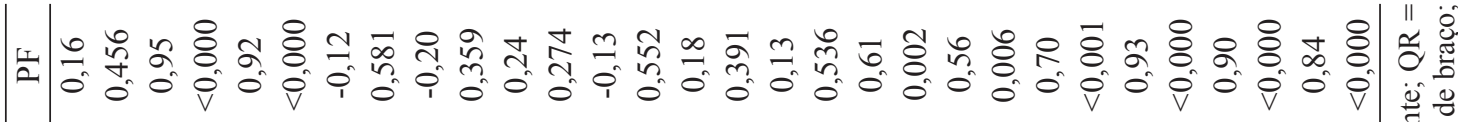

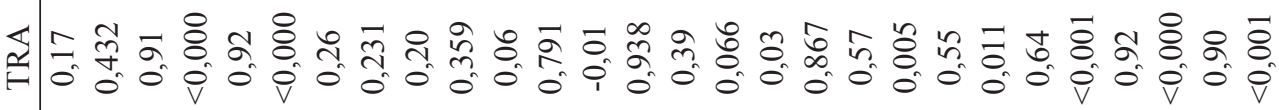

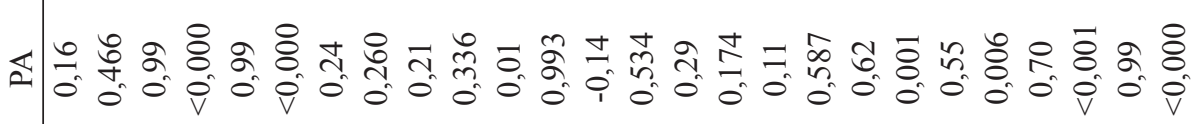

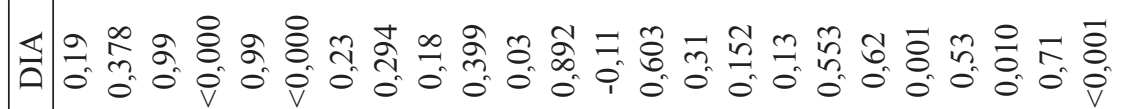

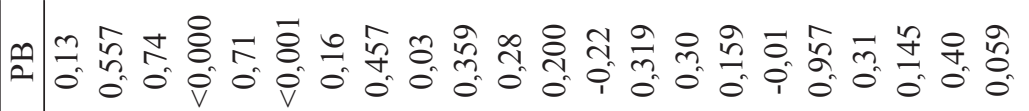

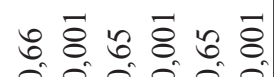

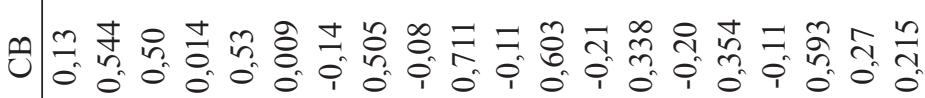

중 กั

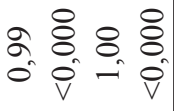

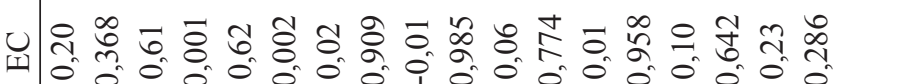

ㄷำ

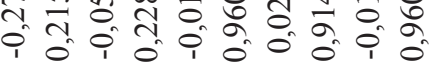

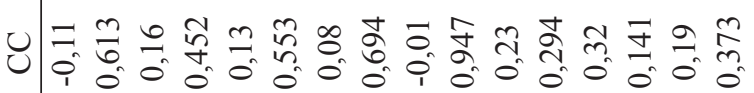

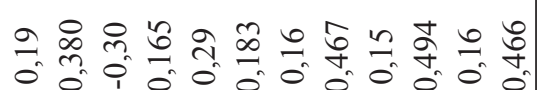

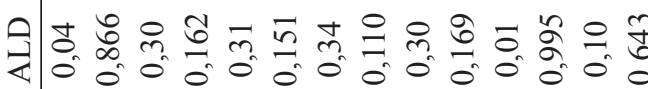

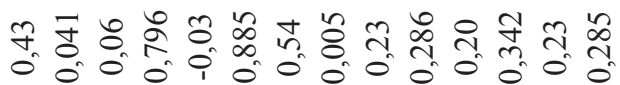

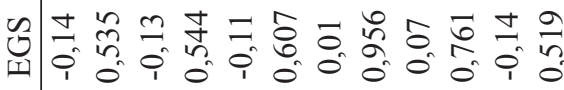

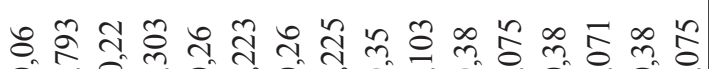

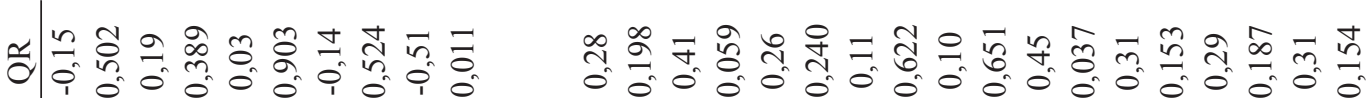

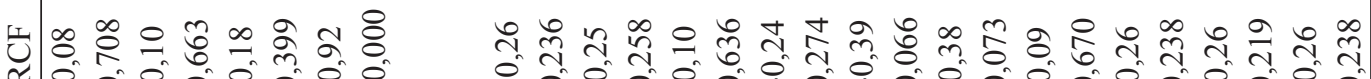

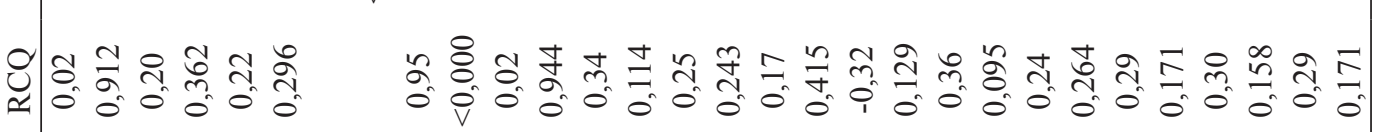

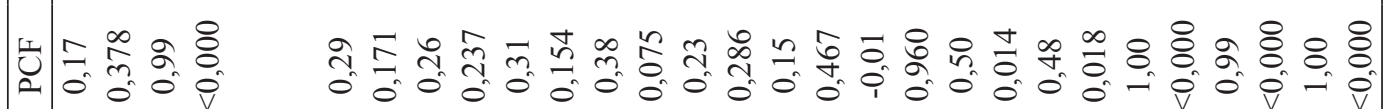
8

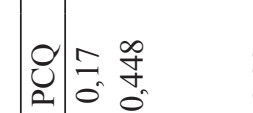

S.

$\sum_{0}$

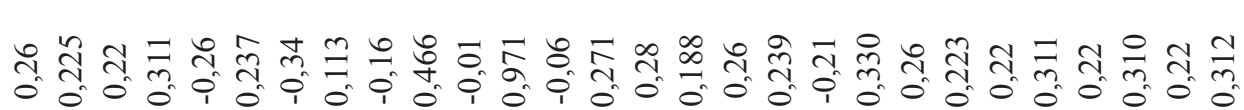

\% 
Vale lembrar que o rendimento de carcaça é influenciado principalmente pelo peso corporal e pelos componentes não integrantes da carcaça (PACHECO et al., 2006; VAZ et al., 2010; PASCOAL et al., 2011). Segundo verificações de Pacheco et al. (2013), o peso corporal foi responsável por 57\% da variação encontrada no rendimento de carcaça fria, enquanto que os componentes não carcaça responderam por $30 \%$ da variação dessa variável. Nesse contexto, Missio et al. (2013) destacam que a medida que o peso corporal aumenta, ocorre maior deposição de músculo e gordura corporal, contribuindo para o aumento do peso de carcaça em relação ao peso de abate, sendo o rendimento de carcaça de importância relativa para os frigoríficos, já que o valor pago ao produtor é em função do peso de carcaça. Além disso, segundo Berg e Butterfield (1976), o rendimento de carcaça é diretamente proporcional ao nível de tecido adiposo presente na carcaça, dentro de um mesmo grupo genético. Devese destacar, no entanto, que os fatores mencionados não podem ser considerados, no presente estudo, como determinantes do rendimento de carcaça, uma vez que tanto o peso de abate como o acabamento das carcaças foi similar entre as dietas.

Animais com predominância genética Nelore apresentaram maior $(\mathrm{P}<0,05)$ rendimento de carcaça que animais com predominância genética Aberdeen Angus (Tabela 2), resultados coerentes com os apresentados na literatura (PEROBELLI; RESTLE; MULLER, 1995; RESTLE et al., 1999; MENEZES et al., 2011). Restle et al. (2000) e Menezes et al. (2011) atribuíram essa diferença ao menor peso relativo de patas, cabeça e, principalmente, do trato gastrintestinal, bem como pelo menor peso e espessura do couro e maior superfície relativa do corpo de zebuínos em relação aos europeus, o que reflete as características adaptativas dos genótipos zebuínos aos climas mais quentes. Além disso, verificou-se que apenas nas carcaças dos animais zebuínos (Nelore) ocorreu correlação significativa (Tabela 4) entre rendimento de carcaça fria e quebra ao descongelamento $(\mathrm{r}=-0,51)$. Isso pode estar relacionado com a distribuição da gordura de cobertura na carcaça, já que essa é depositada em maior quantidade na região cervical, em zebuínos (Bos taurus índicus) e, na região peitoral e sobre os processos espinhosos, nos taurinos (BERG; BUTTERFIELD, 1976). Isso caracteriza menor deposição de gordura no posterior de zebuínos, o que pode resultar em maior perda de líquidos, visto que essa região da carcaça é caracterizada pela maior massa muscular e, consequentemente, com maior quantidade de líquidos armazenada.

A quebra ao resfriamento foi superior $(\mathrm{P}<0,05)$ nas dietas com $66 \%$ de grão de milheto, as quais apresentaram similar quebra ao resfriamento às dietas com $100 \%$ de grão de milho e, essas, por sua vez, apresentaram similar perda de líquidos com as demais dietas (Tabela 2). A quebra ao resfriamento está intrinsecamente associada às características da carcaça, principalmente com a espessura de gordura de cobertura, a qual protege a carcaça do escurecimento pelo frio e da perda de líquidos por desidratação (MÜLLER, 1987). No presente estudo não foi verificado correlação $(\mathrm{P}>0,05)$ da quebra ao resfriamento com a espessura de gordura subcutânea (Tabela 3), bem como com as demais características avaliadas, exceto rendimento de carcaça fria, indicando que outros fatores foram determinantes para sua variação. Restle, Keplin e Vaz (1997), nesse contexto, ponderam que a variação da quebra ao resfriamento pode estar associada a oscilações que ocorrem na câmara fria, como temperatura, velocidade do vento, disposição e número de carcaças. Além disso, Kuss et al. (2005) verificaram que a quebra ao resfriamento diminuiu com o aumento do peso de abate, resultados atribuídos a maior conformação e espessura de coxão, em que a conformação, segundo Arboitte et al. (2004), está negativamente correlacionada com a quebra ao resfriamento e espessura de gordura subcutânea, o que não foi verificado nesse estudo. 
A maturidade fisiológica das carcaças não foi alterada $(\mathrm{P}>0,05)$ pelo teor de milheto na dieta, bem como pelo grupo genético dos animais (Tabela 5). A similaridade na maturidade fisiológica das carcaças, entre as dietas, pode ser explicada pelo similar ganho de peso médio diário, já que a taxa de crescimento é o principal determinante da deposição dos tecidos na carcaça e do peso adulto (NRC, 1996; Di MARCO; BARCELLOS; COSTA, 2007). Já a explicação para a similar maturidade fisiológica entre os grupos genéticos pode ser atribuída ao maior tamanho adulto dos animais com predominância genética Aberdeen Angus, fato evidenciado pelo maior peso de abate destes e seu similar acabamento em relação aos com predominância genética Nelore. Isso infere que a maior taxa de crescimento ocorrida nos novilhos europeus (Aberdeen Angus) permitiu composição tecidual das carcaças similares àquelas de novilhos zebuínos (Nelore), compensando a maturidade corporal mais tardia destes (Di MARCO; BARCELLOS; COSTA, 2007). Esses resultados foram similares aos obtidos por Arboitte et al. (2012), os quais avaliando as características de carcaça de novilhos Aberdeen Angus de frames pequenos e médios, verificaram similar maturidade fisiológica das carcaças, em que os novilhos de frame médio apresentaram maior peso de abate, similar acabamento de carcaça e idade cronológica em relação aos novilhos de frame pequeno.

Os níveis de substituição do grão de milho pelo grão de milheto da dieta e os grupos genéticos não influenciaram $(\mathrm{P}>0,05)$ a espessura de gordura subcutânea (Tabela 5). Os similares acabamentos de carcaças ocorridos entre as dietas experimentais foram resultado do similar ganho de peso médio diário, visto que a taxa de ganho de peso é o principal fator determinante da taxa de deposição de gordura na carcaça (NRC, 1996). Quanto às predominâncias genéticas, o similar acabamento de carcaça pode ser explicado pela ocorrência de similares taxas de deposição de gordura, o que pode ser resultado da compensação entre as taxas de ganho de peso e da composição do ganho. Isso pode ocorrer, pois, embora a taxa de deposição de gordura em relação à taxa de ganho de peso possa ter sido menor nos animais com predominância genética europeia (Aberdeen Angus), em função do maior peso adulto, esses apresentaram maior ganho de peso, enquanto que novilhos com predominância genética zebuína (Nelore) podem ter apresentado maior taxa de deposição de gordura em relação ao ganho de peso, em função do menor peso adulto, mas apresentaram menores taxas de ganho de peso (Di MARCO; BARCELLOS; COSTA, 2007). Destacase também que a cobertura de gordura subcutânea atendeu o requisito mínimo (três milímetros) exigido pelos frigoríficos brasileiros, no intuito de evitar-se a desidratação e o escurecimento da parte externa dos músculos durante o resfriamento, beneficiando a comercialização das carcaças e da carne no atacado.

As características relacionadas com a musculosidade da carcaça como a espessura de coxão, área do longissimus dorsi e conformação não foram influenciadas $(\mathrm{P}>0,05)$ pelo avanço do nível de milheto na dieta (Tabela 5), resultado do similar desenvolvimento corporal atingido ao término do período experimental. De outra maneira, novilhos com predominância genética Aberdeen Angus apresentaram melhor $(\mathrm{P}<0,05)$ espessura de coxão, conformação de carcaça e área do longissimus dorsi, expressa em $\mathrm{cm}^{2}$, em relação aos novilhos com predominância genética Nelore. Quando expressa em relação ao peso de carcaça fria, a área de longissimus dorsi não foi alterada pelos grupos genéticos avaliados. De forma geral, os resultados obtidos foram similares aos encontrados na literatura (PEROBELLI; RESTLE; MULLER, 1995; FATURI et al., 2002; LOPES et al., 2012), em que a justificativa para a maior musculosidade das carcaças de animais de genótipos europeus tem sido atribuída à seleção genética para o desenvolvimento muscular. 
Tabela 5. Variáveis referentes às características qualitativas da carcaça de novilhos com predominância genética Aberdeen Angus (A) ou Nelore (N) alimentados com rações contendo teores de milheto em substituição ao grão de milho.

\begin{tabular}{|c|c|c|c|c|c|c|c|c|c|}
\hline \multirow{2}{*}{ GG } & \multicolumn{4}{|c|}{$\%$ de milheto na dieta } & \multirow{2}{*}{ Média } & \multirow{2}{*}{$\mathrm{CV}$} & \multicolumn{3}{|c|}{ Fontes de variação } \\
\hline & 0 & 33 & 66 & 100 & & & M & GG & $\mathrm{M} * \mathrm{G}$ \\
\hline \multicolumn{10}{|c|}{ Maturidade fisiológica, pontos } \\
\hline A & 13,02 & 12,87 & 11,89 & 12,59 & 12,59 & & & & \\
\hline $\mathrm{N}$ & 12,36 & 12,32 & 12,08 & 12,16 & 12,23 & 6,87 & 0,187 & 0,316 & 0,543 \\
\hline Média & 12,69 & 12,60 & 11,98 & 12,38 & 12,42 & & & & \\
\hline \multicolumn{10}{|c|}{ Espessura de gordura subcutânea (EGS), mm } \\
\hline A & 4,03 & 4,03 & 3,88 & 3,65 & 3,90 & & & & \\
\hline $\mathrm{N}$ & 3,95 & 4,14 & 4,24 & 3,64 & 3,99 & 30,35 & 0,884 & 0,927 & 0,985 \\
\hline Média & 3,99 & 4,08 & 4,06 & 3,65 & 3,95 & & & & \\
\hline \multicolumn{10}{|c|}{ EGS, $\mathrm{mm} / 100 \mathrm{~kg}$ de carcaça fria } \\
\hline A & 1,52 & 1,57 & 1,46 & 1,37 & 1,48 & & & & \\
\hline $\mathrm{N}$ & 1,61 & 1,70 & 1,85 & 1,44 & 1,64 & 29,49 & 0,587 & 0,235 & 0,759 \\
\hline Média & 1,56 & 1,63 & 1,64 & 1,41 & 1,56 & & & & \\
\hline \multicolumn{10}{|c|}{ Área do longissimus dorsi (AOL), $\mathrm{cm}^{2}$} \\
\hline A & 61,35 & 66,98 & 68,55 & 64,49 & 65,34 & & & & \\
\hline $\mathrm{N}$ & 58,09 & 58,12 & 52,32 & 58,80 & 56,83 & 9,71 & 0,689 & $<0,001$ & 0,051 \\
\hline Média & 59,72 & 62,55 & 60,44 & 61,65 & 61,09 & & & & \\
\hline \multicolumn{10}{|c|}{$\mathrm{AOL}, \mathrm{cm}^{2} / 100 \mathrm{~kg}$ de carcaça fria } \\
\hline A & 23,08 & 26,08 & 25,74 & 24,20 & 24,77 & & & & \\
\hline $\mathrm{N}$ & 23,65 & 23,84 & 22,83 & 23,28 & 23,41 & 10,73 & 0,361 & 0,254 & 0,534 \\
\hline Média & 23,36 & 24,99 & 24,40 & 23,75 & 24,12 & & & & \\
\hline \multicolumn{10}{|c|}{ Conformação, pontos } \\
\hline A & 11,48 & 10,64 & 11,63 & 10,94 & 11,17 & & & & \\
\hline $\mathrm{N}$ & 10,65 & 10,25 & 10,04 & 9,83 & 10,19 & 7,46 & 0,123 & $<0,001$ & 0,334 \\
\hline Média & 11,06 & 10,45 & 10,83 & 10,39 & 10,69 & & & & \\
\hline
\end{tabular}

$\mathrm{M}=\%$ de milheto na dieta; $\mathrm{G}=$ grupo genético; $\mathrm{M}^{*} \mathrm{G}=$ interação entre fatores.

Fonte: Elaboração dos autores.

As características de musculosidade da carcaça foram medianamente correlacionadas $(\mathrm{P}<0,05)$ entre si (Tabela 4), resultados discordantes dos verificados por Missio et al. (2013), os quais verificaram elevadas associações entre essas variáveis. De outra maneira, a área do longissimus dorsi e a conformação apresentaram correlações médias/baixas (Tabela 3) com o comprimento de braço $(r=-0,30$ e $r=-0,30$, respectivamente) e perímetro de braço $(\mathrm{r}=0,54$ e $\mathrm{r}=0,41$, respectivamente). O perímetro de braço, nesse contexto, tem grande importância na estimativa da quantidade de músculo na carcaça, uma vez que nessa região os tecidos presentes são basicamente, músculo e osso. Já a correlação negativa entre comprimento de braço e as características de musculosidade de carcaça demonstram a baixa associação entre altura de carcaça e conformação, uma vez que essa característica é avaliada pela hipertrofia muscular (MÜLLER, 1987). Além disso, verificou-se que apenas nas carcaças dos animais com predominância genética Aberdeen Angus ocorreu correlação significativa entre conformação e área do longissimus dorsi (Tabela 4), o que de certa forma se justifica pela maior hipertrofia muscular nesse grupo genético. Deve-se destacar 
que a maior hipertrofia muscular proporciona cortes com melhor aparência, bem como determina menor proporção de osso e maior de porção comestível da carcaça (MÜLLER, 1987; KUSS et al., 2005).

As características métricas da carcaça, exceto comprimento de braço, não foram alteradas pela substituição do grão de milho pelo grão de milheto (Tabela 6). Esses resultados refletiram, em grande parte, o similar desenvolvimento corporal dos animais durante o período experimental. O comprimento de braço foi maior $(\mathrm{P}<0,05)$ para as carcaças dos novilhos alimentados com rações contendo $100 \%$ de grão de milheto em substituição ao milho. Essa variação do comprimento de braço foi uma resposta inesperada, causada provavelmente, por diferenças existentes entre os animais na formação dos lotes no início do experimento, já que essa característica não foi considerada para a seleção dos animais que seriam confinados, pois o critério foi à similaridade quanto ao peso e estado corporal. De outra maneira, novilhos com predominância genotípica europeia apresentaram maior $(\mathrm{P}<0,05)$ perímetro de braço e menor comprimento de braço que novilhos com predominância genética Nelore (Tabela 5). Segundo verificações de Perobelli, Restle e Müller (1995), Restle et al. (1999, 2002), a maior participação de grau de sangue zebuíno no genótipo determinada membros mais compridos e finos e, carcaça mais curta, embora nem sempre essas diferenças sejam evidenciadas (KUSS et al., 2005), já que dependem da composição genética dos animais, bem como da idade fisiológica em que foram realizadas as medidas na carcaça. No presente estudo, os aspectos mencionados ficaram evidentes em função da ocorrência de correlações significativas mais frequentes entre as características métricas e demais características da carcaça nos novilhos com predominância genética da raça Nelore (Tabela 4).

Tabela 6. Variáveis referentes às características métricas da carcaça de novilhos com predominância genética Aberdeen Angus (A) ou Nelore (N) alimentados com rações contendo teores de milheto em substituição ao grão de milho.

\begin{tabular}{|c|c|c|c|c|c|c|c|c|c|}
\hline \multirow{2}{*}{ GG } & \multicolumn{4}{|c|}{$\%$ de milheto na dieta } & \multirow{2}{*}{ Média } & \multirow{2}{*}{$\mathrm{CV}$} & \multicolumn{3}{|c|}{ Fontes de variação } \\
\hline & 0 & 33 & 66 & 100 & & & M & GG & $\mathrm{M}^{*} \mathrm{G}$ \\
\hline \multicolumn{10}{|c|}{ Espessura de coxão, $\mathrm{cm}$} \\
\hline A & 25,91 & 25,58 & 24,99 & 24,91 & 25,35 & & & & \\
\hline $\mathrm{N}$ & 24,41 & 22,68 & 23,34 & 24,42 & 23,71 & 7,04 & 0,418 & 0,002 & 0,407 \\
\hline Média & 25,16 & 24,13 & 24,17 & 24,66 & 24,53 & & & & \\
\hline \multicolumn{10}{|c|}{ Perímetro de braço, $\mathrm{cm}$} \\
\hline A & 37,21 & 37,35 & 37,07 & 36,18 & 36,95 & & & & \\
\hline $\mathrm{N}$ & 36,45 & 35,35 & 34,96 & 36,25 & 35,76 & 4,06 & 0,545 & 0,002 & 0,212 \\
\hline Média & 36,83 & 36,35 & 36,02 & 36,21 & 36,35 & & & & \\
\hline \multicolumn{10}{|c|}{ Comprimento de braço, $\mathrm{cm}$} \\
\hline A & 39,25 & 38,67 & 38,50 & 40,83 & 39,31 & & & & \\
\hline $\mathrm{N}$ & 40,33 & 39,67 & 40,00 & 41,83 & 40,46 & 4,19 & 0,005 & 0,008 & 0,952 \\
\hline Média & $39,79 b$ & $39,17 \mathrm{~b}$ & $39,25 \mathrm{~b}$ & $41,33 \mathrm{a}$ & 39,88 & & & & \\
\hline \multicolumn{10}{|c|}{ Comprimento de perna, $\mathrm{cm}$} \\
\hline A & 73,70 & 73,41 & 72,46 & 75,55 & 73,78 & & & & \\
\hline $\mathrm{N}$ & 73,61 & 76,11 & 74,17 & 75,99 & 74,97 & 3,41 & 0,079 & 0,146 & 0,780 \\
\hline Média & 73,65 & 74,76 & 73,31 & 75,77 & 74,38 & & & & \\
\hline
\end{tabular}

$\mathrm{M}=\%$ de milheto na dieta; $\mathrm{G}=$ grupo genético; $\mathrm{M} * \mathrm{G}=$ interação entre fatores; médias seguidas de letras distintas, na linha, diferem entre si pelo teste Tukey.

Fonte: Elaboração dos autores. 
O peso dos cortes comerciais não foi alterado $(\mathrm{P}>0,05)$ pela substituição do grão de milho pelo de milheto na dieta (Tabela 7), resultado do similar peso de abate, já que essa característica apresentou $(\mathrm{P}<0,05)$ elevada associação com o peso do dianteiro, ponta de agulha e traseiro especial $(r=0,89, r=$ 0,88 e $r=0,89$, respectivamente). Esses resultados foram coerentes com as verificações de Bonilha et al. (2007), os quais avaliaram a seleção para peso pós-desmama em diferentes genótipos e sistemas alimentares e verificaram que a variação do peso de abate influenciou as características correlacionadas, como o peso do traseiro especial, dianteiro e ponta de agulha. Verificou-se ainda, que os pesos dos cortes comerciais apresentaram correlações $(\mathrm{P}<0,05)$ medianas com as características de musculosidade da carcaça e perímetro de braço e, elevadas correlações positivas entre seus pesos, o que indica a possibilidade de aumento do peso destes via seleção para conformação e perímetro de braço, bem como a dificuldade em se promover a alteração na proporção destes. Isso também foi evidenciado por Berg e Butterfield (1976), os quais mencionam que o animal tende a manter, dentro de certos limites, equilíbrio entre os quartos traseiro e dianteiro.

Em relação ao genótipo, verificou-se que animais com predominância genética Aberdeen Angus apresentaram maior $(\mathrm{P}<0,05)$ peso absoluto de dianteiro, ponta de agulha e traseiro especial em relação aos animais com predominância genética Nelore (Tabela 7). Lopes et al. (2012) avaliando as características de novilhos Red Norte (Nelore, Red Angus, Senepol e Caracu) e Nelore verificaram que os animais com predominância europeia apresentam maior peso absoluto dos cortes comerciais, fato relacionado com o maior peso de abate, bem como com a maior musculatura do traseiro especial de bovinos europeus. Kuss et al. (2005) avaliando as características da carcaça de vacas de descarte mestiças Charolês (C) Nelore (N) (3/4Charolês-C Nelore-N, $3 / 4 \mathrm{NC}, 5 / 8 \mathrm{CN}$ e $5 / 8 \mathrm{NC})$, verificaram que animais com predominância genética europeia (3/4 CN) apresentaram maior peso relativo da ponta de agulha que animais com predominância genética zebuína $(3 / 4 \mathrm{NC})$, resultados do maior arqueamento de costelas nos europeus. Deve-se destacar, no entanto, que variações nos pesos dos cortes comerciais nem sempre são encontrados na avaliação entre animais europeus ou zebuínos (FATURI et al., 2002; RESTLE et al., 2002), o que certamente está relacionado com o grau de sangue de cada genótipo, o peso de abate, o acabamento de carcaça e idade dos animais.

Quando expresso em percentagem do peso de carcaça fria, apenas o peso de dianteiro foi alterado, apresentando maior participação na carcaça de animais com predominância genética Nelore (Tabela 7). Segundo Berg e Butterfield (1976), o dianteiro é a parte do corpo que apresenta maior crescimento inicial em relação ao ponta de agulha e traseiro especial, em função das ondas de crescimento atuantes no corpo do animal (da fronte para o posterior e da parte dorsal para a ventral). Além disso, sendo os animais zebuínos mais precoces, em razão do menor peso adulto (Di MARCO; BARCELlOS; COSTA, 2007), os resultados se fazem coerentes, pois esses genótipos apresentaram desenvolvimento do dianteiro em fase mais precoce que os animais com predominância genética europeia. A análise de correlação, realizada em função da predominância genética (Tabela 4), demonstrou também que o peso do traseiro especial apresentou maior associação com o peso corporal nos novilhos europeus (Aberdeen Angus), enquanto nos zebuínos (Nelore), o peso de abate foi mais associado com o dianteiro e ponta de agulha. Deve-se destacar ainda que segundo Luchiari Filho (2000), é desejável que as carcaças apresentem rendimento de traseiro superior a $48 \%$, dianteiro até $39 \%$ e pontade-agulha até $13 \%$, no entanto, no presente estudo, com exceção do rendimento do dianteiro, os demais cortes não se enquadraram nessa recomendação, independente do genótipo utilizado. 
Tabela 7. Variáveis referentes aos cortes comerciais da carcaça de novilhos com predominância genética Aberdeen Angus (A) ou Nelore (N) alimentados com rações contendo teores de grão de milheto em substituição ao grão de milho.

\begin{tabular}{|c|c|c|c|c|c|c|c|c|c|}
\hline \multirow{2}{*}{ GG } & \multicolumn{4}{|c|}{$\%$ de milheto na dieta } & \multirow{2}{*}{ Média } & \multirow{2}{*}{$\mathrm{CV}$} & \multicolumn{3}{|c|}{ Fontes de variação } \\
\hline & 0 & 33 & 66 & 100 & & & M & GG & $\mathrm{M} * \mathrm{G}$ \\
\hline \multicolumn{10}{|c|}{ Dianteiro, $\mathrm{kg}$} \\
\hline A & 104,62 & 98,54 & 100,28 & 105,09 & 102,13 & & & & \\
\hline $\mathrm{N}$ & 96,36 & 93,96 & 91,08 & 98,79 & 95,05 & 5,27 & 0,083 & 0,001 & 0,254 \\
\hline Média & 100,49 & 96,25 & 95,68 & 101,94 & 98,59 & & & & \\
\hline \multicolumn{10}{|c|}{ Dianteiro, $\%$ do peso de carcaça fria } \\
\hline A & 38,97 & 39,04 & 39,02 & 38,54 & 38,89 & & & & \\
\hline $\mathrm{N}$ & 39,05 & 39,01 & 39,08 & 39,00 & 39,04 & 1,01 & 0,074 & 0,001 & 0,496 \\
\hline Média & 39,01 & 39,03 & 39,05 & 38,77 & 38,96 & & & & \\
\hline \multicolumn{10}{|c|}{ Ponta de agulha, $\mathrm{kg}$} \\
\hline A & 38,49 & 36,18 & 36,79 & 41,64 & 38,27 & & & & \\
\hline $\mathrm{N}$ & 35,42 & 35,06 & 33,77 & 36,39 & 35,16 & 9,16 & 0,060 & 0,001 & 0,335 \\
\hline Média & 36,95 & 35,62 & 35,28 & 39,02 & 36,72 & & & & \\
\hline \multicolumn{10}{|c|}{ Ponta de agulha, $\%$ do peso de carcaça fria } \\
\hline A & 14,34 & 14,34 & 14,32 & 15,18 & 14,54 & & & & \\
\hline $\mathrm{N}$ & 14,36 & 14,52 & 14,47 & 14,37 & 14,43 & 5,34 & 0,830 & 0,068 & 0,369 \\
\hline Média & 14,35 & 14,43 & 14,40 & 14,77 & 14,49 & & & & \\
\hline \multicolumn{10}{|c|}{ Traseiro especial, $\mathrm{kg}$} \\
\hline A & 125,35 & 117,65 & 119,86 & 126,19 & 122,26 & & & & \\
\hline $\mathrm{N}$ & 114,92 & 111,93 & 108,27 & 118,11 & 113,31 & 5,58 & 0,119 & $<0,001$ & 0,354 \\
\hline Média & 120,13 & 114,79 & 114,07 & 122,15 & 117,79 & & & & \\
\hline \multicolumn{10}{|c|}{ Traseiro especial, $\%$ do peso de carcaça fria } \\
\hline A & 46,68 & 46,60 & 46,64 & 46,27 & 46,55 & & & & \\
\hline $\mathrm{N}$ & 46,57 & 46,45 & 46,44 & 46,62 & 46,53 & 0,85 & 0,411 & 0,195 & 0,498 \\
\hline Média & 46,63 & 46,53 & 46,54 & 46,44 & 46,54 & & & & \\
\hline
\end{tabular}

$\mathrm{M}=\%$ de milheto na dieta; $\mathrm{G}=$ grupo genético; $\mathrm{M}^{*} \mathrm{G}=$ interação entre fatores.

Fonte: Elaboração dos autores.

\section{Conclusões}

O grão de milheto pode ser utilizado em substituição ao grão de milho, pois não altera as principais características de interesse econômico da carcaça de novilhos terminados em confinamento.

Tourinhos com predominância genética Aberdeen Angus são mais pesados ao abate, apresentam carcaça com maior peso e melhor conformação que tourinhos com predominância genética Nelore.

\section{Referências}

ALMEIDA, R.; MEDEIROS, S. R.; CALEGARE, L.; ALBERTINI, T. Z.; LANNA, D. P. Fazendas de terminação. In: PIRES, A. V. Bovinocultura de corte volume I. Piracicaba: FEALQ, 2010. p. 183-199.

ANUÁRIO DA PECUÁRIA BRASILEIRA ANUALPEC. 21. ed. São Paulo: Instituto FNP, 2014. $313 \mathrm{p}$.

ARBOITTE, M. Z.; BRONDANI, I. L.; RESTLE, J.; FREITAS, L. da S.; PEREIRA, L. B.; CARDOSO, G. dos. S. Carcass characteristics of small and mediumframe Aberdeen Angus young steers. Acta Scientiarum. Animal Sciences, Maringá, v. 34, n. 1, p. 49-56, 2012. 
ARBOITTE, M. Z.; RESTLE, J.; ALVES FILHO, D. C.; PASCOAL, L. L.; PACHECO, P. S.; SOCCAL, D. C. Características da carcaça de novilhos 5/8 Nelore - 3/8 Charolês abatidos em diferentes estádios de desenvolvimento. Revista Brasileira de Zootecnia, Viçosa, v. 33, n. 4, p. 969-977, 2004.

ASSOCIATION OF OFFICIAL ANALYTICAL CHEMISTS - AOAC. Official methods of analysis. $15^{\text {th. }}$ ed. Washington, D.C., 1990. 1141 p.

BERG, R. T.; BUTTERFIELD, R. M. New concepts of cattle growth. New York: Sidney University, 1976. 240 p.

BERGAMASCHINE, A. F.; FREITAS, R. V. L.; VALÉRIO FILHO, W.; BASTOS, J. F. P.; MELLO, S. Q. S.; CAMPOS, Z. R. Substituição do milho e farelo de algodão pelo milheto no concentrado da dieta de novilhos em confinamento. Revista Brasileira de Zootecnia, Viçosa, v. 40, n. 1, p. 154-159, 2011.

BONILHA, S. F. M.; PACKER, I. U.; FIGUEREDO, L. A.; ALLEONI, G. F.; RESENDE, F. D.; RAZOOK, A. G. Efeitos da seleção para peso pós-desmame sobre características de carcaça e rendimento de cortes cárneos comerciais de bovinos. Revista Brasileira de Zootecnia, Viçosa, v. 36, n. 5, p. 1275-1281, 2007.

CAPPELLE, E. R.; VALADARES FILHO, S. C.; SILVA, J. F. C.; CECON, P. R. Estimativas do valor energético a partir de características químicas e bromatológicas dos alimentos. Revista Brasileira de Zootecnia, Viçosa, v. 30, n. 6, p. 1837-1856, 2001.

DI MARCO, O. N.; BARCELLOS, J. O. J.; COSTA, E. C. da. Crescimento de bovinos de corte. Porto Alegre, 2007. $276 \mathrm{p}$.

FATURI, C.; RESTLE, J.; BRONDANI, I. L.; SILVA, J. H. S.; ARBOITTE, M. Z.; CARRILHO, C. O.; PEIXOTO, L. A. O. Características da carcaça e da carne de novilhos de diferentes grupos genéticos alimentados em confinamento com diferentes proporções de grão de aveia e grão de sorgo no concentrado. Revista Brasileira de Zootecnia, Viçosa, v. 31, n. 5, p. 2024-2035, 2002.

HILL, G. M.; NEWTON, G. L.; STREETER, M. N.; HANNA, W. W.; UTLEY, P. R.; MATHIS, M. J. Digestibility and utilization of pearl millet diets fed to finishing beef cattle. Journal of Animal Science, Champaign, v. 74, n. 7, p. 1728-1735, 1996.

KUSS, F.; RESTLE, J.; BRONDANI, I. L.; PASCOAL, L. L.; MENEZES, L. F. G.; PAZDIORA, R. D.; FREITAS, L. da. S. Características da carcaça de vacas de descarte de diferentes grupos genéticos terminadas em confinamento com distintos pesos. Revista Brasileira de Zootecnia, Viçosa, v. 34, n. 3, p. 915-925, 2005.
LICITRA, G.; HERNANDEZ, T. M.; VAN SOEST, P. J. Standardization of procedures for nitrogen fractionation of ruminant feeds. Animal Feed Science and Technology, New York, v. 57, n. 4, p. 347-358, 1996.

LOPES, S. L.; LADEIRA, M. M.; MACHADO NETO, O. R.; PAULINO, P. V. R.; CHIZZOTTI, M. L.; RAMOS, E. M.; OLIVEIRA, D. M. Características de carcaça e cortes comerciais de tourinhos Red Norte e Nelore terminados em confinamento. Revista Brasileira de Zootecnia, Viçosa, v. 41, n. 4, p. 970-977, 2012.

LUCHIARI FILHO, A. Pecuária da carne bovina. São Paulo: R Vieira Gráfica e Editora, 2000. 134 p.

MENEZES, L. F. G.; BRONDANI, I. L.; RESTLE, J.; ALVES FILHO, D. C.; CALLEGARO, A. M.; WEISE, M. Características dos componentes não integrantes da carcaça de novilhos superjovens da raça Devon, terminados em diferentes sistemas de alimentação. Arquivo Brasileiro de Medicina Veterinária e Zootecnia, Belo Horizonte, v. 63, n. 2, p. 372-381, 2011.

MISSIO, R. L.; RESTLE, J.; MOLETTA, J. L.; KUSS, F.; NEIVA, J. N. M.; MOURA, I. C. F. Características da carcaça de vacas de descarte abatidas com diferentes pesos. Revista Ciência Agronômica, Fortaleza, v. 44, n. 3, p. 644-651, 2013.

MÜLLER, L. Normas para avaliação de carcaças e concurso de carcaças de novilhos. 2. ed. Santa Maria: UFSM, $1987.31 \mathrm{p}$.

NATIONAL RESEARCH COUNCIL - NRC. Nutrients requirements of dairy cattle. 7. ed. Washington, D.C.: National Academy Press, 2001. 381 p.

7. ed. Washington, D.C.: National Academy Press, 1996. 242 p.

PACHECO, P. S.; RESTLE, J.; MISSIO, R. L.; MENEZES, L. F. G.; ROSA, J. R. P.; KUSS, F.; ALVES FILHO, D. C.; NEIVA, J. M. N.; DONICHT, P. A. M. M. Características da carcaça e do corpo vazio de bovinos Charolês de diferentes categorias abatidos com similar grau de acabamento. Arquivo Brasileiro de Medicina Veterinária e Zootecnia, Belo Horizonte, v. 65, n. 1, p. 281-288, 2013.

PACHECO, P. S.; RESTLE, J.; SILVA, J. H. S.; BRONDANI, I. L.; PASCHOAL, L. L.; ARBOITTE, M. Z.; FREITAS, A. K. F. de. Desempenho de novilhos jovens e superjovens de diferentes grupos genéticos terminados em confinamento. Revista Brasileira de Zootecnia, Viçosa, MG, v. 34, n. 3, p. 963-975, 2005 a.

PACHECO, P. S.; RESTLE, J.; SILVA, J. H. S.; FREITAS, A. K.; ARBOITTE, M. Z.; PÁDUA, J. T. Relação entre componentes do corpo vazio e rendimentos de carcaça de 
novilhos de corte. Ciência Animal Brasileira, Goiânia, v. 7, n. 2, p. 107-113, 2006.

PACHECO, P. S.; SILVA, J. H. S. da; RESTLE, J.; ARBOITTE, M. Z.; BRONDANI, I. L.; ALVES FILHO, D. C.; FREITAS, A. K. de. Características quantitativas da carcaça de novilhos jovens e superjovens de diferentes grupos genéticos. Revista Brasileira de Zootecnia, Viçosa, MG, v. 34, n. 5, p. 1666-1677, 2005 b.

PASCOAL, L. L.; VAZ, F. N.; VAZ, R. Z.; RESTLE, J.; PACHECO, P. S.; SANTOS, J. P. A. Relações comerciais entre produtor, indústria e varejo e as implicações na diferenciação e precificação de carne e produtos nãocarcaça. Revista Brasileira de Zootecnia, Viçosa, v. 40, p. 82-92, 2011. Suplemento.

PEROBELLI, Z. V.; RESTLE, J.; MÜLLER, L. Estudo das carcaças de vacas de descarte das raças Charolês e Nelore. Pesquisa Agropecuária Brasileira, Brasília, v. 30, n. 3, p. 409-412, 1995.

PEROTTO, D.; ABRAHÃO, J. J. S.; MOLETTA, J. L. Características quantitativas de carcaça de bovinos zebu e de cruzamentos Bos taurus x Zebu. Revista Brasileira de Zootecnia, Viçosa, v. 29, n. 6, p. 2019-2029, 2000. Suplemento 1 .

PETHICK, D. W.; HARPER, G. S.; ODDY, V. H. Growth, development and nutritional manipulation of marbling in cattle: a review. Australian Journal Experimental Agriculture, Collingwood, v. 44, n. 7, p. 704-715, 2004.

RESTLE, J.; KEPLIN, L. A. S.; VAZ, F. N. Características da carcaça de novilhos Charolês, abatidos com diferentes pesos. Pesquisa Agropecuária Brasileira, Brasília, v. 32, n. 8, p. 851-856, 1997.

RESTLE, J.; PASCOAL, L. L.; FATURI, C.; ALVES FILHO, D. C.; BRONDANI, I. L.; PACHECO, P. S.; PEIXOTO, L. A. Efeito do grupo genético e da heterose nas características quantitativas da carcaça de vacas de descarte terminadas em confinamento. Revista Brasileira de Zootecnia, Viçosa, v. 31, n. 1, p. 350-362, 2002. Suplemento.

RESTLE, J.; VAZ, F. N.; FEIJÓ, G. L. D.; BRONDANI, I. L.; ALVES FILHO, D. C.; BERNARDES, R. A. C.; FATURI, C.; PACHECO, P. S. Características de carcaça de bovinos de corte inteiros ou castrados de diferentes composições raciais Charolês e Nelore. Revista Brasileira de Zootecnia, Viçosa, v. 29, n. 5, p. 1371-1379, 2000.
RESTLE, J.; VAZ, F. N.; QUADROS, A. R. B.; MÜLLER, L. Características de carcaça e da carne de novilhos de diferentes genótipos de Hereford $\mathrm{x}$ Nelore. Revista Brasileira de Zootecnia, Viçosa, v. 28, n. 6, p. 1245-1251, 1999.

SILVA, A. H. G.; RESTLE, J.; MISSIO, R. L.; BILIGO, U. O.; FERNANDES, J. J. R.; REZENDE, P. L. P.; SILVA, R. M.; PEREIRA, M. L. R.; LINO, F. A. Milheto em substituição ao milho na dieta de novilhos confinados. Semina: Ciências Agrárias, Londrina, v. 35, n. 4, p. 2077-2094, 2014.

SILVA, D. J.; QUEIROZ, A. C. Análise de alimentos: métodos químicos e biológicos. 3. ed. Viçosa, MG: UFV, 2002. $235 \mathrm{p}$.

VAN SOEST, P. J. Collaborative study of acid-detergent fiber and lignin. Journal of the Association of Official Analytical Chemists, Washington, v. 56, n. 4, p. 781-784, 1973.

VAN SOEST, P. J.; ROBERTSON, J. B.; LEWIS, B. A. Methods for dietary fiber, neutral detergent fiber, and nonstarch polyssacarides in relation to animal nutrition. Journal of Animal Science, Collingwood, v. 74, n. 10, p. 3583-3597, 1991.

VAZ, F. N.; RESTLE, J.; ALVES FILHO, C. C.; BRONDANI, I. L.; PASCOAL, L. L.; VAZ, R. Z.; PEIXOTO, L. A. Características de carcaça e da carne de novilhos filhos de vacas $1 / 2$ nelore $1 / 2$ charolês e $1 / 2$ charolês $1 / 2$ nelore acasaladas com touros charolês ou nelore. Revista Brasileira de Zootecnia, Viçosa, v. 31, n. 4, p. 1734-1743, 2002.

VAZ, F. N.; RESTLE, J.; ARBOITE, M. Z.; PASCOAL, L. L.; FATURI, C.; JONER, G. Fatores relacionados ao rendimento de carcaça e novilhos ou novilhas superjovens, terminados em pastagem cultivada. Ciência Animal Brasileira, Goiânia, v. 11, n. 1, p. 57-65, 2010.

VAZ, F. N.; RESTLE, J.; SILVA, N. L. Q.; ALVEZ FILHO, D. C.; PASCOAL, L. L.; BRONDANI, I. L.; KUSS, F. Nível de concentrado, variedade da silagem de sorgo e grupo genético sobre a qualidade da carcaça e da carne de novilhos confinados. Revista Brasileira de Zootecnia, Viçosa, v. 34, n. 1, p. 239-248, 2005.

WHEELER, T. L.; CUNDIFF, L. V.; KOCH, R. M.; CROUSE, J. D. Characterization of biological types of cattle (Cycle IV): carcass traits and longissimus palatability. Journal of Animal Science, Collingwood, v. 4, n. 5, p. 1023-1035, 1996. 
